\title{
Cross-disciplinary supervision amongst social workers in Aotearoa New Zealand
}

\author{
Jo Hutchings, Lareen Cooper and Kieran O'Donoghue
}

Jo Hutchings is a registered social worker with a private practice in the Tasman District. Lareen Cooper is the Director of Social Work and Social Policy at Massey University, Palmerston North. Kieran O'Donoghue is the Head of the School of Health and Social Services at Massey University.

\begin{abstract}
Cross-disciplinary supervision is occurring amongst social workers in Aotearoa New Zealand and it is regarded positively. However, the findings of this research involving 54 social workers who are members of the Aotearoa New Zealand Association of Social Workers (ANZASW) indicates there is a) no clear understanding of what constitutes cross-disciplinary supervision; b) potential for issues to arise and c) a need for guidelines. The results are discussed in terms of developing knowledge, practice competence and accountability in relation to the practice of cross-disciplinary supervision and a framework for cross disciplinary supervision is presented.
\end{abstract}

\section{Introduction}

For the purposes of this study cross-disciplinary supervision was defined as a supervision practice occurring between practitioners from differing professional and/or disciplinary backgrounds (O'Donoghue, 2004). Forces influencing its development include managerialism; cost cutting or rationalisation of services; the growth of the private practice industry; the development of integrative, and collaborative approaches to social service provision. In addition, supervision is also becoming a feature of practice for other professions, paraprofessions and non-professionals where previously it was not (Berger \& Mizrahi, 2001; Bogo, Paterson, Tufford, \& King, 2011; Cooper, 2006; Lin, Goodale, Villanueva, \& Spitz, 2007; Mullarkey, Keeley \& Playle, 2001; O’Donoghue, 2004; Simmons, Moroney, Mace, \& Shepherd, 2007).

Associated with the emergence of cross-disciplinary supervision has been a debate regarding supervisor training. Advocates for a generic model of supervision are increasingly pursuing the development of a universal supervision practice, as opposed to discipline/ profession specific models of supervision, for the health and social service sectors. This has the potential to both promote and increase the practice of cross-disciplinary supervision (Crocket, et al., 2009; Davys \& Beddoe, 2008; Morrell, 2003; O’Donoghue \& Tsui, 2011; Rains, 2007).

The extent that cross-disciplinary supervision practice is occurring amongst ANZASW members is relatively unknown. The primary objectives of this paper and the research reported within it are to: 1) describe the prevalence of cross-disciplinary supervision amongst 
ANZASW members, 2) explain the nature of cross-disciplinary supervision and 3) examine ANZASW members' views about cross-disciplinary supervision.

\section{Literature review}

The literature search included both databases and the bibliographies of key journal articles on cross-disciplinary supervision. Databases searched were Academic Search Premiere, Google Scholar, Scopus, JSTOR, ERIC, PsychINFO and MEDLINE. Bibliographies searched included: Berger \& Mizrahi (2001); Hyrkas, Appelqvist-Schmidlechner, \& Paunonen-Ilmonen (2002); Kavanagh, et al. (2003); Mullarkey et al. (2001); O'Donoghue (2004); and Spence, Wilson, Kavanagh, Strong, \& Worrall (2001). The three key themes identified were the prevalence, nature of and views on cross-disciplinary supervision. The terms used in the literature search included history, social work, supervision, cross-disciplinary, inter-disciplinary, multi-disciplinary, trans-disciplinary, cross-professional, inter-professional, multi-professional and trans-professional.

\section{The prevalence of cross-disciplinary supervision}

The practice of cross-disciplinary supervision within Aotearoa New Zealand was identified by Cooper \& Anglem (2003, p.22) where six (15.4\%) of 41 social workers provided cross-disciplinary supervision and three $(7.7 \%)$ of 39 social workers received cross-disciplinary supervision. O'Donoghue, Munford \& Trlin (2005, p.49) found that 79 (51.6\%) of 153 ANZASW social work respondents reported they were participating in cross-disciplinary supervision. A third study (Beddoe and Howard, 2012, p.186) indicated that 54.3\% of 174 social work supervisees reported receiving cross-disciplinary supervision at least monthly.

International literature also demonstrated that cross-disciplinary supervision is occurring amongst social workers and appears to be increasing. For example, Berger \& Mizrahi (2001, p.15- 16) followed up changes in the supervisory practices of social workers between 1992 and 1996. During the first 12-month period $12 \%(\mathrm{~N}=40)$ of 340 respondents participated in cross-disciplinary supervision. This increased to $16 \%(\mathrm{~N}=54)$ of 340 in the next 12-month period and $19 \%(\mathrm{~N}=56)$ of 311 in the final 12-month period.

\section{The nature of cross-disciplinary supervision}

Beddoe and Howard's (2012) study identified reasons why social workers engaged in cross-disciplinary supervision. These included that an own-profession supervisor was not available, a lack of skills on the part of the supervisor, the need for cultural supervision, a positive supervisory relationship in the past, being a requirement for the role and the supervisor having an understanding of the work context of the supervisee.

In relation to the profession or discipline of cross-disciplinary supervisors, Cooper \& Anglem (2003) noted that social workers used nurses and a psychologist. In contrast, social work supervisors' cross-disciplinary supervisees were nurses, an occupational therapist, a Maori health worker and a doctor.

The majority of cross-disciplinary supervisors in Beddoe and Howard's (2012, p.186) study appeared to have supervisor training of more than one day's duration. A postgraduate qualification was indicated by $17.8 \%$ of participants while just over half reported no official qualification. 
It appeared that most supervisors in Beddoe and Howard's (2012, p.186-7) study did not take clinical responsibility for cross-disciplinary supervisee practice with only $16.8 \%$ indicating they did. This is surprising when $47.8 \%$ of the social work supervisees in their study reported cross-disciplinary supervision as the only form of supervision they accessed.

\section{Views about cross-disciplinary supervision}

It was apparent in the research literature that cross-disciplinary supervision was generally valued by participants, but a number of challenges are also identified. Aspects of cross-disciplinary supervision considered valuable by respondents in Townend's (2005, p.585-7) study were identified as 'different perspectives', 'increased creativity', 'wider knowledge', 'prevents becoming complacent' and 'critical thinking'. Similar themes were reported by Beddoe and Howard (2012, p.187) and included 'usefulness of different approaches', 'increases my knowledge', 'facilitates creative thinking', 'more creative outcomes', 'enhances understanding of other professional approaches' and 'helps me question my institutional approach'. Cross-disciplinary supervisors' view from 'outside' the discipline is also noted as a potential contribution (Crockett, et al., 2009). While Hyrkas et al. (2002) reported that multi-professional team supervision promoted relationships, communication and multi-professional practice within teams. Improvement of professional identity within the multi-professional team was also noted.

Themes considered to be a challenge for cross-disciplinary supervision were identified by Townend (2005, p.585-7) as, 'professional role and training differences and misunderstandings', 'difference in training level', 'absence of shared theories and language', 'absence of empathy for organisational issues' and 'fear of revealing weaknesses'. In terms of addressing the challenges evident for cross-disciplinary supervision, there were a number of recommended guidelines presented. The first of these was in relation to the need for a comprehensive supervision contract that clearly defines the participants, purpose, nature, process, scope and limitations. Associated with this was the need for ongoing review of supervision contracts and relationships (Beddoe \& Howard, 2012; Mullarkey et al., 2001; O’Donoghue, 2004; Simmons, Moroney, Mace \& Shepherd, 2007). Understanding the similarities and differences of professional supervision traditions as well as personal experiences of supervision for participants was the next recommendation for mitigating challenges for cross-disciplinary supervision. Associated with this was a need to acknowledge and address difference in status (Beddoe \& Howard, 2012; O’Donoghue, 2004; Townend, 2005).

The need for awareness of and familiarity with each other's code of ethics, professional practice standards, professional values and complaint processes was also identified. A related theme was the need to ensure sufficient shared background knowledge to recognise the role of training on practice and preferred ways of working (Beddoe \& Howard, 2012; O’Donoghue, 2004; Simmons et al., 2007; Townend, 2005).

That cross-disciplinary supervision practice needs to sit within agency, policy, regulatory and professional practice guidelines was a further recommendation. This requires an appropriate understanding of the relevant organisation, professional association and regulatory contexts and requirements. Furthermore, cross-disciplinary supervision should occur as an authorised activity and only be provided as additional to supervision that is professionally mandated (Beddoe \& Howard, 2012; Davys \& Beddoe, 2008; O'Donoghue, 2004; Simmons et al., 2007; Townend, 2005). 
The need for own-disciplinary supervision for discipline-specific tasks and competencies was evident in the research undertaken by Bogo et al. (2011), Mullarkey et al. (2001) and Kavanagh et al. (2003). Additionally, the frequency of contact with same-discipline supervisors was linked to perceived impact on practice, while contact with cross-disciplinary supervisors was not (Kavanagh et al., 2003). Cross-disciplinary supervision is therefore regarded as useful for experienced practitioners, however not recommended for new graduates or practitioners (Mullarkey et al., 2001; Simmons et al., 2007).

Overall, the cross-disciplinary supervision literature highlighted the lack of a research, theory or knowledge base for this practice. The need for further research to better monitor and understand cross-disciplinary supervision, develop appropriate knowledge, skills and guidelines, and to evaluate its effectiveness were clear recommendations (Beddoe \& Howard, 2012; Berger \& Mizrahi, 2001; Mullarkey et al., 2001; O’Donoghue, 2004; Simmons et al., 2007; Townend, 2005). Lastly, there is a view that supervision has become a profession in its own right and learning to become a supervisor is a generic rather than profession-specific process. As such, a need for a common philosophy for clinical supervision has been suggested (Davys \& Beddoe, 2008; Mullarkey et al., 2001; Spence et al., 2001).

\section{Methodology}

A survey research design was chosen as the best approach to practically explore and describe social workers' participation in and their views about cross-disciplinary supervision. Data collection involved a self-administered, web-based internet survey questionnaire. This method was chosen as the most effective way of accessing the descriptive data required on a national basis (Babbie, 2007; De Vaus, 2002).

The survey questionnaire design included a review of survey questionnaires used previously in research on supervision and research that was related to cross-disciplinary supervision (e.g. Beddoe \& Howard, 2012; Berger \& Mizrahi, 2001; Kavanagh et al, 2003). However, a specifically designed questionnaire was required for this research and consisted of four separate sections with a total of 75 closed questions and three open questions. These 78 questions collected data on 107 variables which were concerned with: a) general characteristics, b) the prevalence of cross-disciplinary supervision, c) the nature of the cross-disciplinary supervision, and d) views about cross-disciplinary supervision. The survey questionnaire was constructed using the online survey tool known as SurveyMonkey (www.surveymonkey.com).

The survey population for this research was ANZASW members. This population was chosen due to their presumed identification as social workers, adherence to ANZASW supervision policy and their accessibility through the ANZASW. The link to the survey questionnaire was initially distributed to 267 ANZASW members. Due to a low response rate however, it was decided to include convenience sampling. Fifty-four useable questionnaires were completed, resulting in a response rate of $20.2 \%$.

\section{Data analysis}

The online survey data from the 54 questionnaires was analysed using PASW Statistics 18 (predictive analytics software) (http:/ / www.spss.com). Cross checks were undertaken at regular intervals during the data entry process and again on completion to ensure accuracy in data entry. 
The second part of the data analysis process involved a univariate descriptive analysis being undertaken for each question. The analysis for the closed questions included frequency and percentage measures, while the scale item variables were analysed using mean and standard deviation measures. Bivariate cross-tabulations were also undertaken on a number of variables to explore whether a range of respondents' general characteristics had any association with participation in cross-disciplinary supervision.

\section{Limitations of the methodology}

The lower-than-expected response rate meant that the results cannot be generalised beyond the respondents and is a key limitation of the research. The use of a convenience sample together with the low response rate also meant that significance tests could not be applied. Despite these limitations the data collected does provide a portrait of the prevalence and nature of and views about cross-disciplinary supervision among a group of 54 ANZASW members. It therefore provides a basis for comparison in further studies of this topic (Babbie, 2007; De Vaus, 2002).

\section{Results}

\section{The prevalence of cross-disciplinary supervision amongst ANZASW social workers}

Amongst the 54 participants, 25.9\% ( $\mathrm{N}=14$ ) received cross-disciplinary supervision, 29.6\% $(\mathrm{N}=16)$ provided cross-disciplinary supervision and $44.5 \%(\mathrm{~N}=24)$ both provided and received cross-disciplinary supervision. The gender distribution of respondents was $77.8 \%(\mathrm{~N}$ $=42)$ female and $22.2 \%(\mathrm{~N}=12)$ male. In terms of ethnic origin $68.5 \%(\mathrm{~N}=37)$ of respondents self-identified as New Zealand European or Pakeha, $11.1 \%(\mathrm{~N}=6)$ as other European, 5.6\% $(\mathrm{N}=3)$ as Maori, 7.4\% $(\mathrm{N}=4)$ as New Zealand European and Maori, 3.7\% $(\mathrm{N}=2)$ as Other, $1.9 \%(\mathrm{~N}=1)$ as New Zealand European and Pacific Peoples, and 1.9\% $(\mathrm{N}=1)$ as Asian.

The majority of respondents reported that participation in cross-disciplinary supervision occurred on a regular or more frequent basis and that it occurred at least monthly. Cross-disciplinary supervision was more prevalent in hospital or health services, community agency or private practice employment settings and this is possibly due to these services being more interdisciplinary or multidisciplinary in their practice. It also appeared that cross-disciplinary supervision was more prevalent amongst practitioners at advanced levels of practice, with more years of social work experience, undertaking further training or working in major or provincial cities or towns, who identified with another discipline in addition to social work and who belonged to an additional professional membership organisation.

\section{The nature of cross-disciplinary supervision}

A formally contracted individual supervisory relationship was the most frequently experienced type of cross-disciplinary supervision. Adhoc consultations, ongoing informal case consultations and multidisciplinary team meetings were also identified as cross-disciplinary supervision and experienced on a regular basis. The 'one-on-one' mode of cross-disciplinary supervision was received by the majority of participants $(\mathrm{N}=31 ; 81.6 \%)$. Likewise, among those who provided cross-disciplinary supervision the majority $(\mathrm{N}=31 ; 81.6 \%)$ also provided 'one-on-one' supervision. Thirty $(81.1 \%)$ respondents who received and $33(94.3 \%)$ who provided cross-disciplinary supervision indicated that it occurs on a planned basis. The predominant reasons given for both receiving and providing cross-disciplinary supervision were: 'the supervisor is knowledgeable about my work context' and 'I require a supervisor from another profession or discipline to 
develop specific skills and/or knowledge'. Most respondents who received cross-disciplinary supervision 34 (91.9\%) indicated they had influence over who provided their cross-disciplinary supervision. In contrast, those who provided cross-disciplinary supervision had less influence over who they provide supervision to, with $26(76.5 \%)$ indicating they did.

Among the 38 participants who received cross-disciplinary supervision almost three quarters $(\mathrm{N}=28 ; 73.7 \%)$ reported this relationship as external to their employing agency, while for the remainder $(\mathrm{N}=10 ; 26.3 \%)$ it was internal. Among those whose cross-disciplinary supervision was external, $10(35.7 \%)$ practised in a community agency, nine (32.1\%) in private practice, six $(21.4 \%)$ in a hospital or health service and three $(10.8 \%)$ across the child welfare, justice and school settings. Eight of the 10 participants who received internal cross-disciplinary supervision worked in a hospital or health service, one in a community agency and another in a tertiary training institute. Fourteen (53.8\%) of the 26 participants who provided external cross-disciplinary supervision worked in private practice, seven (26.9\%) in a hospital or health service, and eight (19.3\%) across the remaining fields of practice. Of the eight participants who identified the cross-disciplinary supervision they provide is internal three $(37.5 \%)$ worked in a hospital or health service, three $(37.5 \%)$ in child welfare and two $(25.0 \%)$ in a community agency.

Cross-disciplinary supervision was mostly authorised by the agency management structures for both those who received and provided it (with 83.8\%; $\mathrm{N}=31$ of the former and $94.1 \% ; \mathrm{N}=32$ of the latter). Thirty-eight participants indicated that their cross-disciplinary supervisor had undertaken supervisor training, whereas amongst those who provided supervision, supervision training had been undertaken by $27.5 \%(\mathrm{~N}=11)$ who had completed a short course, 27.5\% ( $\mathrm{N}=11)$ had a certificate qualification, $25.0 \%(\mathrm{~N}=10)$ attended a workshop, 22.5\% ( $\mathrm{N}=9)$ held a diploma qualification and 15.0\% $(\mathrm{N}=6)$ indicated 'other'.

Twenty-five (65.8\%) of the 38 respondents who received cross-disciplinary supervision indicated they were aware of their cross-disciplinary supervisor's code of ethics. Whereas, $31(83.8 \%)$ participants indicated that their cross-disciplinary supervisor was aware of the ANZASW code of ethics. Twenty-six (72.2\%) were aware of their supervisor's complaints process. The cross-disciplinary supervisor's awareness of ANZASW standards for practice was indicated by 26 (70.3\%) of 37 participants. Twenty-five participants (65.8\%) also received supervision from an ANZASW social worker in addition to cross-disciplinary supervision. Among these participants $18(72.0 \%)$ reported this as 'one on one', five (20.0\%) as 'peer', one $(4.0 \%)$ as 'group', and $1(4.0 \%)$ as 'other'. Overall, the most frequently reported frequency that supervision was received from an ANZASW social worker was 'monthly'.

Twenty-nine $(90.6 \%)$ of 32 respondents who provided cross-disciplinary supervision were aware of their cross-disciplinary supervisee's participation in supervision with someone from their own professional group.

Thirty of the 38 respondents who received cross-disciplinary supervision, had a supervision contract in place and for 25 of them, it was a written contract. In comparison, 31 of 33 participants who provided cross-disciplinary supervision had a contract in place and all indicated this contract was written. Seven $(20.6 \%)$ of 34 respondents who received cross-disciplinary supervision indicated that their supervisor had clinical and / or professional responsibility for their social work practice. 
In contrast, among those participants $(\mathrm{N}=33)$ who provided cross-disciplinary supervision $13(39.4 \%)$ indicated they had clinical and/or professional responsibility for their cross-disciplinary supervisee's practice. Overall, more participants reported use of cross-disciplinary supervision for developmental and resourcing functions than the qualitative function. This possibly reflects the qualitative function being addressed in the supervisee's own discipline supervision. Overall, in terms of the nature of cross-disciplinary supervision the findings indicated that there was no unified understanding of what constitutes cross-disciplinary supervision, although it appeared to be both similar and different to social work supervision. It was typified by formally contracted individual supervisory relationships that predominantly occurred for developmental and educative purposes and to a large extent was in addition to own-disciplinary supervision.

\section{ANZASW social workers' views about cross-disciplinary supervision}

Participants were positive about the overall level of effectiveness they experienced with cross-disciplinary supervision. They also generally agreed that it enhanced practice. The receipt of supervision from a social work supervisor in addition to a cross-disciplinary supervisor was associated with higher ratings. There was general agreement amongst participants that cross-disciplinary supervision enhanced practice due to encouraging critical thinking and creativity, increasing ability to work collaboratively and understand other professional approaches, and through experience of different theories and perspectives. The majority of participants agreed that cross-disciplinary supervision is effective where it facilitates reflective practice, challenges professional assumptions, facilitates practice development, the supervisor is an expert, it occurs regularly and it is in addition to own-profession/discipline supervision. This indicates that criteria for effectiveness in cross-disciplinary supervision are to a large extent similar to that for social work supervision. Six participants who received cross-disciplinary supervision, however, strongly disagreed with the criterion that 'it is in addition to own-profession/ discipline supervision' and did not receive supervision from a social worker.

All participants indicated a level of importance for each statement drawn from O'Donoghue's (2004) guidelines for cross-disciplinary supervision. These statements are essentially based in ethical considerations, practice standards and regulation and as such are important in terms of accountable, mandated, safe and competent practice and included:

- the scope of the supervision is clearly established;

- all parties are informed about each other's ethical codes and complaints processes;

- there is an explicit contract covering the nature, purpose and structure of the supervision;

- the status of the supervision in relation to regulatory professional membership and organisational requirements is clear and explicit;

- the similarity and differences between each profession's supervision traditions are discussed;

- experiences of supervision are discussed by the individuals involved;

- it is authorised by the organisation; and

- it is provided only on the condition that when it concerns a health practitioner or a practitioner from a profession with an established supervision culture and policy, that it is additional to their professionally mandated supervision.

There were two statements that were attributed a notably lower importance rating by respondents. These were: a) 'it is authorised by the organisation'; and b) 'it is provided 
only on the condition that when it concerns a health practitioner or a practitioner from a profession with an established supervision culture and policy, that it is additional to their professionally mandated supervision'.

On average participants tended to be at least satisfied with the different functions of cross-disciplinary supervision. This would indicate that to some extent cross-disciplinary supervision is contributing to the developmental, resourcing or qualitative needs of supervisees. Overall, there was a low level of agreement among participants that cross-disciplinary supervision also hindered practice. The main areas where they thought it hindered practice were: a) the absence of shared theories / language; b) professional differences and misunderstanding about supervision c) the inability to address professional role issues, d) the fear of revealing area/s for professional growth/development, and e) professional status issues.

\section{Discussion}

There were a number of implications emerging from the findings regarding the prevalence and nature of and views about cross-disciplinary supervision. These are discussed in terms of their meaning for social workers, ANZASW and the Social Workers Registration Board of New Zealand (SWRB), training providers, employing agencies and organisations, other professional groups, a practice framework and further research regarding cross-disciplinary supervision.

\section{Social workers}

Clearly, social workers engage in both providing and receiving cross-disciplinary supervision. Implicit in this is the need for policy, guidelines and research relating to the practice of cross-disciplinary supervision to reflect consideration for the various roles that social workers take and the potential differences that exist for supervisors and supervisees.

A number of participants in this study appeared to be unaware of the ANZASW requirement of attending core social work supervision at least monthly. Information regarding supervision and competency requirements is readily available to ANZASW social workers and knowledge of these is an integral aspect of professional practice. A key impact of this is that cross-disciplinary supervisors will need to actively promote cross-disciplinary supervision as an adjunct to own-disciplinary supervision with their supervisees.

The possibility that social work supervision was perhaps not being realised by a few participants who received cross-disciplinary supervision suggests a need for supervisees to be more aware of their rights and responsibilities in the supervision process. This supports O'Donoghue's (2010) finding of the need for supervisee education and development in relation to the supervisory process.

While some ANZASW social workers identified the purpose of cross-disciplinary supervision as developmental and educative, very few participants appeared to identify it as continuing professional development. In essence, the development of knowledge and/ or skills through cross-disciplinary supervision could constitute continuing professional development from an ANZASW and/or SWRB perspective (ANZASW, 2011; SWRB, 2010).

There was agreement amongst participants that cross-disciplinary supervision can both enhance and occasionally hinder practice and that certain criteria and guidelines would 
enhance the overall effectiveness of it. The risks reinforce the need for regular own-disciplinary supervision to occur alongside of cross-disciplinary supervision. It also further highlights that new practitioners do require own-discipline supervision. It also reinforces the importance of undertaking regular evaluation in cross-disciplinary supervision practice to ensure that supervision needs are in fact being adequately and appropriately met. The development of policies and guidelines should assist supervisors and supervisees to reflect carefully, from both perspectives, the appropriateness of cross-disciplinary supervision. It could also assist in organisational policy development. This survey highlights some key factors to consider in cross-disciplinary supervision and the following framework (Figure one) is suggested to assist practitioners and organisations. This highlights key factors in developing cross-disciplinary supervision.

Figure one. Framework for cross-disciplinary supervision.

\section{Cross-disciplinary supervision}

Additional to core social work supervision

Authorised by agency

Aware of legal, ethical and regulatory requirements

Knowledge of own and one another's ethical codes, practice standards and complaints process

Knowledgeable of differences in supervision histories and traditions

Trained supervisor

Clinical responsibility remains with the supervisee

Completed, clearly written contract is in place

Establish the driver for cross disciplinary supervision - why?

\section{ANZASW \& SWRB}

There were a number of key areas where the participants in this study appeared to not be meeting competency and/or registration requirements. These included the need to attend core supervision and at least monthly, having a written supervision contract, and awareness about the need for accountability and a mandate in supervision practice. This signals a lack of awareness or perhaps different interpretations of ANZASW supervision policy and/or SWRB supervision requirements by some members (ANZASW, 2009; SWRB, 2009.

The lack of detailed guidelines in relation to cross-disciplinary supervision by both the ANZASW and SWRB possibly compounds this situation. There is a clear need for education and awareness to be developed amongst social workers about regulatory and policy factors that impact on cross-disciplinary supervision. Also implied is the need for clear, consistent and accessible guidelines which specify supervision requirements in relation to cross-disciplinary supervision. A good starting point for these would be the guidelines proposed by O’Donoghue (2004, p.6).

The ANZASW requirement that social work supervisors have completed social work supervisor training may require further consideration where the provision of cross-disciplinary supervision is undertaken. Generic supervisor training is potentially supported by the practice of cross-disciplinary supervision, however, additional supervisor training that is appropriate for the different disciplinary fields within which cross-disciplinary supervision is occurring may be required. 
It may be useful for ANZASW and SWRB to work with other professional groups/membership bodies to develop specific guidelines regarding participation in cross-disciplinary supervision.

\section{Training providers}

The implications for training providers are in relation to the need for education and development of both supervisees and supervisors in the practice of cross-disciplinary supervision and about the requirements to supervise social workers.

Professional social work and supervision education and training programmes potentially provide an opportunity for further education amongst social workers and social work students about the requirements for supervision. This could include more specific training regarding supervision policy. They also provide an opportunity for educating and developing supervisees in terms of their understanding, expectations, responsibilities and role in supervisory processes.

Further consideration in relation to what discipline-specific training or knowledge development may be required in addition to generic supervisor training for supervising own-disciplinary and cross-disciplinary supervisees.

\section{Employing agencies/organisations}

While this study did not specifically collect information from participants regarding the existence or awareness of agency supervision policy, it did appear from the research process that not all agencies had clear or accessible supervision policy. Given legislative and professional organisation policy and / or requirements exist in relation to social work supervision practice, it would seem appropriate for agencies and organisations employing social workers to ensure that supervision policy is consistent with and aligns to these.

\section{Other professional groups}

There appeared to be a lack of awareness by cross-disciplinary supervisors about ANZASW codes of ethics and practice standards. Implicit in this is the need for other professional groups to also consider and develop awareness about potential generic requirements or guidelines for participation in cross-disciplinary supervision. There is also the potential role for cross-disciplinary supervisors from other professional groups to promote cross-disciplinary supervision as an adjunct to own-disciplinary supervision.

\section{Cross-disciplinary supervision practice framework}

Cross-disciplinary supervision is a new area of practice arising from both need and opportunity. As a consequence, it lacks formal models or frameworks as practitioners are relying on their practice knowledge and wisdom to inform their work. However, this research highlights key areas that could form the development of a new framework for cross-disciplinary supervision that aims to cover the essential features of this relationship.

\section{Further research}

The research reported confirms that cross-disciplinary supervision within Aotearoa New Zealand is a practice that requires further research and development. The following recommendations suggest that future research in the area:

- Considers the prevalence of cross-disciplinary supervision amongst registered social workers. 
- Clearly defines the terms related to cross-disciplinary supervision, which would minimise potential for misunderstandings to emerge.

- Monitors change in the prevalence of cross-disciplinary supervision.

- Explores social workers' awareness of and access to existent agency policy and/or guidelines for cross-disciplinary supervision by specifically including questions in relation to this.

- Examines the differences and similarities which are being identified and discussed in the cross-disciplinary supervision process.

- Explores the views of practitioners from other disciplines regarding cross-disciplinary supervision with social workers.

- Explores why some social workers are using cross-disciplinary supervision as a replacement for own-disciplinary supervision.

- Explores the provision of supervision by social workers to non- or paraprofessionals.

- Tests the framework developed.

\section{Conclusion}

Cross-disciplinary supervision does occur amongst the members of ANZASW as an adjunct to own-discipline supervision or even replacing it. The cross-disciplinary supervision engaged in by social workers in this survey appeared to be predominantly one on one, external, authorised and involving choice of supervisor or supervisee. It occurred primarily for developmental and educative reasons and was largely in addition to own-disciplinary supervision. While this group of ANZASW social workers generally viewed cross-disciplinary supervision positively, the potential for issues was acknowledged and general agreement with the need for guidelines was indicated. This relatively new area of practice has evolved to meet needs and implications for supervisees and supervisors from social work as well as other professions and requires more work than this study can cover. The authors recommend further research to understand the practice competencies, knowledge base and accountabilities required and the further development of a practice framework to inform practitioners.

\section{References}

Aotearoa New Zealand Association of Social Workers. (2009). ANZASW supervision policy. Christchurch, New Zealand: ANZASW.

Aotearoa New Zealand Association of Social Workers. (2010). Personal communication October 2010. Christchurch, New Zealand: ANZASW.

Aotearoa New Zealand Association of Social Workers. (2011). Continuing professional development policy. Christchurch, New Zealand: ANZASW.

Babbie, E. (2007). The practice of social research (11th Ed). USA: Thomson Higher Education.

Beddoe, L., \& Howard, F.M. (2012). Interprofessional supervision in social work and psychology: Mandates and (inter) professional relationships. The Clinical Supervisor, 311, 178-202.

Berger, C., \& Mizrahi, T. (2001). An evolving paradigm of supervision within a changing health care environment. Social Work in Health Care, 32 (4), 1-18.

Bogo, M., Paterson, J., Tufford, L., \& King, R. (2011). Interprofessional clinical supervision in mental health and addiction: Toward identifying common elements. The Clinical Supervisor, Volume, 30(1), 124-140.

Cooper, L. (2006). Clinical supervision: Private arrangement or managed process? Social Work Review, XVIII (3), 21-30.

Cooper, L., \& Anglem, J. (2003). Clinical supervision in mental health. Australian Centre for Community Services Research: Adelaide.

Crocket, K., Cahill, F., Flanagan, P., Franklin, J., McGill, R., Stewart, A., Whalan, M., \& Mulcahy, D. (2009). Possibilities and limits of cross-disciplinary supervision: An exploratory study. NZ Journal of Counselling, 29(2), 25-43.

Davys, A., \& Beddoe, L. (2008). Interprofessional learning for supervision: 'Taking the blinkers off'. Learning in Health and Social Care, 8(1), 58-69. 
De Vaus, D. (2002). Surveys in social research (5th Ed). Australia: Allen \& Unwin.

Hyrkas, K., Appelqvist-Schmidlechner, K., \& Paunonen-Ilmonen, M. (2002). Expert supervisors' views of clinical supervision: A study of factors promoting and inhibiting the achievements of multiprofessional team supervision. Journal of Advanced Nursing, 38(4): 387-397.

Kavanagh, D.J., Spence, S.H., Strong, J., Wilson, J., Sturk, H., \& Crow, N. (2003). Supervision practices in allied mental health: Relationships of supervision characteristics to perceived impact and job satisfaction. Mental Health Services Research, 5(4), 187-195.

Lin, I., Goodale, B., Villanueva, K., \& Spitz, S. (2007). Supporting an emerging workforce: Characteristics of rural and remote therapy assistants in Western Australia. Australian Journal of Rural Health, 15: 334-339.

Morrell, M. (2003). Forethought and afterthought - two of the keys to professional development and good practice in supervision. Social Work Review, XV(1 \& 2): 29-32.

Mullarkey, K., Keeley, P., \& Playle, J.F. (2001). Multiprofessional clinical supervision: Challenges for mental health nurses. Journal of Psychiatric and Mental Health Nursing, 8:, 205-211.

O'Donoghue, K. (2004). Social workers and cross-disciplinary supervision. Social Work Review, XVI(3): 2-7.

O'Donoghue, K. (2010). Towards the construction of social work supervision in Aotearoa New Zealand: A study of the perspectives of social work practitioners and supervisors. PhD thesis, Massey University, Palmerston North.

O'Donoghue, K., Munford, R., \& Trlin, A. (2005). Mapping the territory: Supervision within the Association. Social Work Review, XVII(4): 46-64.

O'Donoghue, K., \& Tsui, M. (2011). Towards a professional supervision culture: The development of social work supervision in Aotearoa New Zealand. International Social Work, http: / / isw.sagepub.com. /. (Accessed 16/03/2011).

Rains, E. (2007). Interdisciplinary supervisor development in a community health service. Social Work Review, XIX(3): 58-65.

Simmons, H., Moroney, H., Mace, J., \& Shepherd, K. (2007). In D. Wepa (Ed). Clinical supervision in Aotearoa/New Zealand: A health perspective (pp. 72 - 86). New Zealand: Pearson Education.

Social Workers Registration Act 2003. Wellington: New Zealand Government.

Social Workers Registration Board (2009). Supervision expectations for registered social workers. Policy statement.

Social Workers Registration Board (2010). Entitlement to registration: Continuing professional development policy. Policy statement.

Spence, S., Wilson, J., Kavanagh, D., Strong, J., \& Worrall, L. (2001). Clinical supervision in four mental health professions: A review of the evidence. Behaviour Change, 18(3), 135-155.

Townend, M. (2005). Interprofessional supervision from the perspectives of both mental health nurses and other professionals in the field of cognitive behavioural psychotherapy. Journal of Psychiatric and Mental Health Nursing, 12, 582-588.

Tsui, M. (2005). Social work supervision: Contexts and concepts. Thousand Oaks, CA: Sage. 